REVIEW PAPER

\title{
Behavioural addictions in children and adolescents
}

\author{
Iwona Grzegorzewska $a^{A, E, F, G}$ \\ University of Zielona Gora, Poland
}

The emergence in DSM-5 of gambling addiction as the first official behavioural addiction has opened a new chapter in the thinking about and research into behavioural pathology. We are becoming increasingly aware of the causes, mechanisms and consequences of addictive behaviour, but the majority of the work is conducted mainly on adult populations. Although the use of the term "behavioural addiction" in children and adolescents is controversial due to the dynamic nature of their development processes, there is no doubt that more and more young people are involved in addictive behaviours that negatively affect their lives. The currently still few studies are throwing new light on the early symptoms of behavioural addictions observed in increasingly younger children.

This article is a review of current knowledge about potential behavioural addictions in the first two decades of life viewed from the perspective of developmental psychopathology. While there is significantly less research into addictive behaviours in childhood and adolescence than in later decades, empirical evidence has clearly shown that early symptoms of behavioural addiction pose a significant threat to the mental health of children and adolescents, both now and in the future. The article discusses the definition of behavioural addiction in the DSM-5 context, the controversy surrounding the diagnosis of these disorders in young people, the behavioural addictions in children and adolescents, and the identified risk factors for early-onset behavioural addictions.

\section{KEY WORDS}

gaming; gambling; childhood and adolescence; addiction; risk and protective factors

CORRESPONDING AUthoR - Prof. Iwona Grzegorzewska, University of Zielona Gora, 69 Wojska Polskiego Str., 65-762

Zielona Gora, Poland, e-mail: ia.g@interia.pl

AUthors' CONTRIBUtion - A: Study design - B: Data collection - C: Statistical analysis - D: Data interpretation .

E: Manuscript preparation · F: Literature search · G: Funds collection

TO CITE THIS ARTICLE - Grzegorzewska, I. (2017). Behavioural addictions in children and adolescents. Current Issues in

Personality Psychology, 5(3), 206-214.

RECEIVED 30.03.2017 · REVIEWED 5.04.2017 · ACCEPTED 13.04.2017 · PUBLISHED 22.09.2017 


\section{BACKGROUND}

When we think of addiction, the most common associations are with alcohol, drugs or cigarettes. However, for a long time it has been observed that addiction may be linked to a variety of behaviours (e.g. gambling, shopping, using the internet, computer games, work) that a person cannot control and which negatively affect many areas of life. The goal of such people is not so much to achieve pleasure as to reduce the feeling of being unwell and internal tension. Behavioural addictions are a type of mental addiction (non-substance), pathologically attested by the strong urge to carry out these activities, their frequency and intensity. Over the past two decades, the interest of researchers in the problem of non-substance addiction has increased considerably. The emergence in DSM-5 of gambling addiction as the first official behavioural addiction has opened a new chapter in the thinking about and research into behavioural pathology. We are becoming increasingly aware of the causes, mechanisms and consequences of addictive behaviour, but the majority of the work is conducted mainly on adult populations. Although the use of the term "behavioural addiction" in children and adolescents is controversial due to the dynamic nature of their development processes, there is no doubt that more and more young people are involved in addictive behaviours that negatively affect their lives. Problematic use of the internet, video games and gambling and compulsive overeating is increasingly being diagnosed in adolescents and young adults (Rosenberg \& Feder, 2014), and the currently still few studies are throwing new light on the early symptoms of behavioural addictions observed in increasingly younger children.

The literature clearly indicates the similarity of behavioural addictions to addiction to psychoactive substances (Petry, 2015). This similarity is due both to the phenotypic picture of both disorders and to the common mechanisms underlying them. This allows us to use at least part of the knowledge about the trajectory of addiction development in young people to understand the mechanisms responsible for certain addictive behaviours. Thanks to the prospect of developmental psychopathology including in its analysis of disorders rules and norms concerning normative development, it is possible to gain a new perspective on the start and consolidation of addictive behaviours in young people (Cierpiałkowska \& Grzegorzewska, 2016).

\section{BEHAVIOURAL ADDICTIONS IN THE LIGHT OF THE DSM-5}

Among clinicians, it has long been believed that there are behaviours that lead to a short-term reward, which causes people to continue such behaviour despite the negative effects associated with it. This applies both to the use of psychoactive substances and to certain behaviours such as playing video games or using a mobile phone. The reduced control of an individual over his own behaviour, despite his knowledge of the harmfulness, is central to linking substance and non-substance addiction. This similarity has led to the introduction of the concept of "behavioural addiction" or "non-substance addiction", as similar to addictions to psychoactive substances.

The term "behavioural addiction" is not easy to define, and using it to describe problem behaviours, especially in children and young people, evokes many controversies. The central concept is based on certain behaviours and their repetition in spite of the negative consequences of them. Until recently, non-substance-related behavioural addiction was not mentioned in any of the major medical classifications - neither in the classification of psychiatric disorders of the American Psychiatric Association DSM-IV (APA, 2000) nor in the International Statistical Classification of Diseases and Health Problems ICD-10 (WHO, 1992). The revised DSM 5 (APA, 2013) introduces significant changes in thinking about psychoactive substance abuse and obsessive-compulsive behaviour. First and foremost, gambling-related disorders (DSM-III - compulsive gambling, DSM-IV - pathological gambling) have been linked to substance addictions and have been acknowledged as an empirically supported prototype of behavioural addictions. Currently, these are the only disorders recognised officially as a non-substance addiction, despite the widespread interest of clinicians in behaviours such as "addiction to pornography", "addiction to video games", "workaholism" and "addiction to food". The most likely candidate for recognition as the next behavioural addiction is "internet addiction", but for now existing empirical evidence only allows it to be considered as potentially possible for inclusion in the category of non-substance-related disorders and addictions.

Other addictive behaviours were considered either to require further research (e.g. addiction to video games) or to be to subject to deliberation but so far excluded from the classification of behavioural addictions due to the lack of satisfactory empirical evidence (e.g. shopping, exercise, sex).

\section{BEHAVIOURAL ADDICTIONS FROM THE PERSPECTIVE OF DEVELOPMENTAL PSYCHOPATHOLOGY}

According to the latest scientific knowledge, psychiatric disorders, including addiction, should be treated as a complex, dynamically developing process of 
changes and deviations in the functioning of an individual. These changes commonly occur throughout life, much earlier than the main symptoms of addiction. Until very recently, addictions were discussed only in the context of adults, or early symptoms in late adolescence. More and more often, however, it is pointed out that symptoms characteristic for these disorders are observed in children and can be an obstacle to the proper development of individuals before they reach adulthood.

We gain wide insights into mental disorders and mental health, non-adaptation and adaptation, and interactions between them through developmental psychopathology. It allows us to see addiction as a complex phenomenon dependent on many mutually related conditions, including vulnerability, biopsychosocial risk factors, and personal engagement (Cierpiałkowska, 2010; Juczyński, 2008; Poprawa, 2015). In analyses of behavioural addictions, three approaches are particularly important. First, research into normative development is crucial for understanding pathology in development (Cicchetti, 1993, 2013). At the base of normal and disturbed development are the same processes, so discoveries and theories for proper development are important to explain the development of disorders and psychopathology. Analysis of determinant factors for the risk of behavioural addictions should take into account the many related and complementary elements. It must take into account both factors related to vulnerability and factors related to resistance to disorders. The pathways that healthy and disturbed development follow depend on the interaction of risk and protective factors throughout the entire life of an individual, taking into account the dynamic processes of balancing requirements (including life stresses, developmental tasks and social expectations) at a specific stage of development and in a specific life context. In order to carefully analyse individual behavioural addictions, it is therefore necessary to specifically address both the risk (understood as the factors responsible for susceptibility to addiction and the factors that directly initiate and sustain addictive behaviours) and protective factors (understood as individual resilience, coping factors and personal potentials).

In modern models of addiction, it is assumed that factors of vulnerability and resilience are related to biological, psychological and environmental predispositions. Giving consideration to these is indispensable to adequately describe and understand the mechanisms of addiction and good adaptation. This is especially important for young people because their increased neuronal sensitivity to the so-called rewarding behaviour leading to addiction has been documented (Tapert, Caldwell, \& Burke, 2005). The rewarding function is also performed by various addictive behaviours, so it can be assumed that compared to adults, including in the case of behaviour such as playing video games or eating, there is also increased vulnerability among young people to the development of addictive mechanisms. The way an individual copes with his or her life (whether or not it is effective, adaptive or not) depends on matching their resources to life requirements (Rutter et al., 1997; Sameroff, 2000; Cierpiałkowska \& Grzegorzewska, 2016; Grzegorzewska \& Cierpiałkowska, 2017). In the case of young people more than adults, the quality of their family and peer environment plays a significant role. The origins of behavioural addiction development begin with environmental factors that include easy access to and social acceptance of behaviours. For example, in the case of pathological gambling, it means modelling playing for money at home and among peers (see Blaszczynski \& Nower, 2002), and as epidemiological studies show, the earliest gambling behaviour among children occurs when it is possible to raise even a small amount of money, and the home environment facilitates and promotes gambling (Jacobs, 2000). Ladouceur, Dube, and $\mathrm{Bu}-$ jold (1994) found that $40 \%$ of children gamble once a week or more and most of them participate with their parents in lotteries (59\%), card games (53\%) and betting on sporting events (48\%). Other studies have shown that parents of children aged 11-15 buy them lottery tickets (71\%) and scratch cards (51\%) (Wood \& Griffiths, 1998). From empirical data, it is well known that easy access to gambling, modelling in the family and early gaming experience are associated with higher rates of pathological gambling in early adulthood (see Blaszczynski \& Nower, 2005). Secondly, it is not possible to gain a complete understanding of the development of behavioural addiction without analysing the pathways leading up to and following addictive behaviours.

These pathways are usually complex, and their various substrates and determining factors can lead to the same results (equifinality), or similar initial conditions result in varied developmental effects (equipotentiality) (Cicchetti \& Rogosch, 1996). This means that not all addicted people are the same (they constitute a heterogeneous group), and each pathway differs in terms of the presence or absence of psychosocial and biological vulnerability factors and behavioural addictions. As a consequence, in order to achieve effectiveness in therapy, each pathway requires different forms and methods of therapy. The development of pathways leading to behavioural addiction during adolescence and later is still poorly understood, and the dynamics of change observed during childhood development and adolescence dictate that care must be taken when evaluating behavioural addiction in young people (Grzegorzewska \& Cierpiałkowska, 2017). However, some analyses are already taking place in this area. For example, in Blaszczynski and Nower's (2002) vulnerability aetiological model of behavioural addictions, based on 
the concept of pathological gambling as a mental disorder, at least three pathways of addiction were identified: pathway 1 - behavioural, pathway 2 emotional vulnerability, and pathway 3 - temperamental vulnerability based on impulsiveness. The behavioural addiction process is initiated by environmental factors, then passes through one of the three isolated pathways, and ends with the development of habits related to desire and the empowerment of specific behaviours, despite the negative effects that derive from them. Each of the pathways is associated with dynamically related risk factors and protective factors of a clinical nature. The model is confirmed in empirical studies, although in none of them have all the factors been tested at the same time.

Thirdly, analyses undertaken from the perspective of developmental psychopathology emphasise continuity and changes in development (Trempała \& Cieciuch, 2016), which in the case of behavioural addictions means the need to treat them dimensionally, especially in children and adolescents. This is particularly important because of the growing amount of evidence that confirms the hierarchical and dimensional nature of psychopathology (Krueger \& Markon, 2011; Ofrat \& Krueger, 2012). According to the literature, addictions are increasingly treated not only as qualitatively different categories (a person either is or is not addicted), but also as gradual, quantifiable increases in harmful symptoms of addictive behaviours (Krueger, Markon, Patrick, Benning, $\&$ Kramer, 2007). A less categorical and more dimensional approach to addiction is evident in the latest DSM 5 (2013) classification.

\section{DIAGNOSTIC PROBLEMS OF BEHAVIOURAL ADDICTIONS IN CHILDREN AND ADOLESCENTS}

Evaluating addictive behaviours and potential behavioural addictions in young people is important for several reasons. First, taking into account the findings of developmental psychopathology, it is worth noting that the first symptoms that indicate the possibility of developing addictions appear during adolescence or earlier (Hawkins \& Fitzgibbon, 1993; Bachman, Wadsworth, O'Malley, Johnston, \& Schulenberg, 1997), and the full diagnosis of substance addiction appears in early adulthood, and increasingly often also during adolescence (Chassin, Sher, Hussong, \& Curran, 2013). The literature on substance addition indicates that early exposure to psychoactive substances (e.g. alcohol, nicotine) raises the risk of developing substance addictions during adulthood. It is believed that this risk is associated with increased biological vulnerability and greater life stress (Cierpiałkowska \& Grzegorzewska, 2016). Similar mechanisms are likely to be responsible for the development of potential behavioural addictions in young people. For example, in Rehbein's longitudinal studies (2013), 15-year-olds with symptoms of addiction to video games showed many specific symptoms typical of addictive behaviours already at the age of 10 years. Early detection of disturbing behavioural signals increases the chances of preventing adverse developmental outcomes and preventing the development of substance addictions in the future. Preventive measures should be aimed at relatively young children before the full symptoms of dependency on selected behaviours emerge. They should also be targeted taking into account the life situations and contexts of young people's development. Secondly, during late childhood and adolescence, children experience many cumulative stress situations related to puberty, education and social needs. Parental influence is diminished, with a significant increase in the role of the peer group. The weakening of parental ties results in increased vulnerability to peer pressure, which can lead to many problems. Peer pressure can mediate in the development of pathological behaviours, including the acquisition of psychoactive substances and other addictive behaviours (Wölfling \& Müller, 2009; Grzegorzewska, 2013). Taking up these behaviours results in a change in the perception of the family situation, which in turn leads to the illusion that there are no problems resulting from unfavourable perceptions of their family situation and the exacerbation of problem behaviours (Streit \& Oliver, 1972). Early recognition of the symptoms of behavioural addictions in young people can be used to break the chain of negative consequences.

There is still a lot of doubt in the literature as to how to define and, therefore, what diagnostic criteria to adopt for individual behavioural addictions. The most commonly accepted criteria are those adopted for substance dependence and applied to gambling disorders: 1 . Undertaking a given activity in order to change mood: gaining pleasure, reducing pain, increasing energy, calming or, in the final phase, maintaining the ability to function (tolerance effect); 2. Over time, the need to intensify a given activity in order to achieve a desirable/acceptable state; 3 . Loss of control over the amount, frequency and duration of certain activities; 4. Appearance of withdrawal symptoms, if the performance of the action is shortened, limited or impossible to achieve, and 5. Exacerbation of negative consequences resulting in exceeding the time devoted to the performance of a given activity, which is a direct or indirect indicator of loss of control (APA, 2013).

Among children and adolescents, the diagnosis of potential addictive behaviours is far more problematic than in adults. First of all, the specific development and functioning of children and adolescents should be taken into account, because the criteria used for adults are not always appropriate for the behaviour 
of young people. This implies the need to prepare versions of scales for the diagnosis of behavioural addictions in children/adolescents, because many diagnostic methods prepared for adults cease to be accurate and reliable for young people. It is important to take into account the contexts of young people's development, the specificity of their activity and their level of development. For example, the Yale Food Addiction Scale (YFAS) (Gearhardt, Corbin, \& Brownell, 2009) for the diagnosis of addiction to food has the modified YFAS-C version for children (Gearhardt, Roberto, Seamans, Corbin, \& Brownell, 2013), which takes into account development characteristics, including the activity of children (e.g. vocational activity in the scale for adults was changed to school activity) and relationships with parents. Questions were also modified to improve clarity to fit the level of development (e.g. "When I start to eat a particular product I eat much more than I planned" is replaced by "When I start eating I cannot stop") (Gearhardt et al., 2009; Gearhardt et al., 2013).

It is worth remembering that in clinical practice, a comprehensive approach to assessing mental health and disorders has diagnostic importance, particularly in relation to children and adolescents.

This means that only using "paper and pencil" methods to assess the level of involvement in specific behaviour and estimating potential addiction problems is insufficient. Also necessary is a deeper medical history, observation and collection of information from many sources (the child, parents and teachers).

Diagnostic problems are also related to the variability and dynamics of development processes. In studies by Compas, Heiden, and Gerhardt (1995) on trajectories of development pathways in adolescents their heterogeneity was clearly shown. Although development is perceived as a coherent, ordered and targeted process (from initial adaptation patterns to later established paths of development), it is also characterised by flexibility, intermittency and change. According to this principle, adolescent development can be relatively stable or variable. Stable paths are associated with adolescents growing up in a low-risk environment (adapted pathway) or adolescents experiencing difficulty from early childhood and excessive chronic stress or trauma (non-adapted path). Paths that vary over time are associated with people in whom non-adaptation is limited only to the period of adolescence or those who function much better in adolescence than in childhood, or those in whom adolescence means a permanent worsening in the level of functioning. The variability and instability of developmental paths for children and adolescents can result from positive or negative changes in a young person's environment (e.g. transition to middle school, parental divorce, death of a loved one, change in parental attitudes) and biological and developmental changes (e.g. a developmentally deter- mined vulnerability to risky behaviour) or hereditary factors appearing only in adolescence (Compas et al., 1995). The stability and variability of development in relation to addictive behaviour are confirmed by the longitudinal studies by Gentile (2011). The important observation resulting from these studies to underline is that the pathological playing of video games during childhood and adolescence cannot be treated as a transient problem. During the 2-year study of more than 3,000 children aged 10-11 and 14-15 years, $84 \%$ of the pathological players revealed in the first study were still playing addictively after two years. Also, in the same 2-year period, only $1 \%$ of players became addicted to playing. This means that the pathological playing of video games cannot be considered as a "phase" or "stage" in the development of a child that passes with time. The early symptoms of behavioural addictions that appear in childhood are important predictors of serious problems in the future.

\section{FUNCTIONS OF ADDICTIVE BEHAVIOURS IN CHILDREN AND ADOLESCENTS}

Behaviours such as playing computer games, gambling, sports, eating or shopping serve many purposes: entertainment, relaxation, experiencing a sense of competence and independence, or escape from everyday problems (Griffiths, 2003; Ryan, Rigby, \& Przybylski, 2006). These behaviours (such as the use of video games) in children and adolescents can lead to a state of trance where the sense of time and place disappears, and there is a sense of control, power, and extreme inner satisfaction (Gentile et al., 2009). Such behaviours are not initially threatening, but may become pathological if they lead to negative consequences in everyday life. The central function in this process is played by the reward mechanism, or the subjective sense of pleasure. At the beginning of each addiction is pleasure and satisfaction. A prize is intended to motivate and encourage adaptation. Mechanisms, structures and transmitters responsible for the development of addiction are constantly being studied: documented biological mechanisms of addictive behaviour are the role of neurotransmitters (dopamine) and the cerebral reward system (mainly the mesolimbic pathway).

The compulsive engagement of young people in various forms of pathological behaviour can fulfil many important functions in their development. In general, the two most important are satisfying the need for stimulation and coping with stress (Grzegorzewska \& Cierpiałkowska, 2017). The need for stimulation is related to the temperamental characteristics of the individual, which for a long time have been identified as important personal correlates of 
behavioural habits (see Cierpialkowska, 2010). Although this is primarily related to substance abuse, more and more studies confirm their importance also in relation to behavioural addictions (Petry, 2016; Maclaren, Fugelsang, Harrigan, \& Dixon, 2011; Goudriaan, Oosterlaan, De Beurs, \& Van Den Brink, 2008), including in children and adolescents (Conrod et al., 2013; Moffitt et al., 2011).

The assumption that is popular in the literature that children use games as a way of coping with stress is extremely simplified. Although children often use play as a mechanism to deal with many difficult life situations, it is not a simple exemplification of their problems. Gentile's (2011) study shows that children who started playing pathologically during the study were more likely to have depression, anxiety, and social anxiety, and children who stopped playing during the study had lower levels of depression, anxiety and social phobia. This means that intense play intensifies mental health problems in young people and contributes to the development of disorders. In the literature, it is also emphasised that addictive behaviours can be a form of compensation for intrapersonal deficits such as low self-esteem or identity problems (Nimtz, Griffiths, \& Baynard, 2005; Israelashvili, Kim, \& Bukobza, 2012). For example, during adolescence, one of the most important development tasks is to achieve personal autonomy and independence from parents. Development of identity and simultaneous maintenance of closeness with parents is a very stressful task. Teenagers who have trouble with this task may prefer to use the Internet to deal with excessive tension and distress. The Internet, and especially social media, give users an opportunity to create their own identity, which is not possible in the real world. Thanks to the ability to post photos and select information about themselves, each user can create an image of themselves that they consider the most beneficial and attractive. Thus, the Internet can be an easy and accessible means of experimenting with different images of oneself, which allows one to cope with the difficulties associated with defining oneself (Koo \& Kwon, 2014; Grzegorzewska \& Cierpiałkowska, 2017). Immediate positive reinforcement achieved through being active online and the ease of building a virtual self can be the cause of receiving instant gratification and increased engagement, and consequently can lead to addiction.

Another function of addictive behaviours is to build relationships with others. For example, thanks to active participation in social media, young people can satisfy their needs for belonging and acceptance. Social media are a very attractive form of maintaining social contacts due to immediate access that crosses financial, geographical and time constraints. The ability to create an image that masks imperfections is an advantage as well as a safe form of communication that allows control over what is said and minimises stress. The problem, however, is that social media increasingly replace real face-toface contact with other people (Davies \& Cranston, 2008) and actually create the illusion of belonging to a social group and having interpersonal relations (Grzegorzewska \& Cierpiałkowska, 2017).

\section{RISK FACTORS AND FACTORS PREVENTING ADDICTIVE BEHAVIOURS}

The identification of individual differences in the developmental paths of young people is closely related to the identification of those factors that put individuals at risk of non-adaptive development and those that protect against the development of addiction despite exposure to risk (Garmezy, 1985; Rutter, Rutter, 1985; Grzegorzewska, 2013). Risk factors are those related to the personality of the individual or their environment that increase the probability of developing disorders. Protective factors, however, hypothetically interact with risk factors, reducing the likelihood of disorders (Compas et al., 1995; Cierpiałkowska \& Grzegorzewska, 2016). Existing research into risk factors and protective factors for potential behavioural addictions in children and adolescents focuses primarily on addiction to video games and the Internet. Current empirical data point primarily to potential threats, while there is less knowledge on protective factors.

Among the basic risk factors for addictive behaviours are age and sex. It is well known that children and adolescents are interested in new experiences and are more likely to use the "virtual world" than adults and more often undertake various activities. The latest research indicates that young people are more likely to fall into addiction due to immature brain structures (Petry, 2015; Grzegorzewska $\&$ Cierpiałkowska, 2017). In adolescence, up to about 20 years of age, the prefrontal cortex is still growing and is not finally formed, and this area of the brain is responsible for executive functions, including decision making, attention, the ability to express emotions and working memory (Filip, 2013). Recent neurobiological studies have shown that the development of adolescents is characterised by gaps between changes in the dopaminergic reward system (increasing the search for sensations and seeking rewards from puberty) and the gradual and slower development of cognitive control that correlates with increased myelination of the prefrontal cortex and in cortical and pre-cortical areas (Paus, 2005). This gap between an increasing need for reward and stimulation and slower development of cognitive control predisposes adolescents to risky behaviour (Steinberg, 2008). At the same time, the latest neurobiological studies show that the presence of peers activates the same reward centres, which in turn increases risky behaviours (Chein, Albert, O’Brien, Uckert, \& Steinberg, 2011). 
These findings corroborate studies directly on behavioural addictions. For example, some addictions (e.g. pathological gambling) usually start in childhood or adolescence in men faster than in women (Chambers \& Potenza, 2003; Grant \& Kim, 2001), as in the patterns for substance addiction. Likewise, this is the case with regard to the pathological playing of video games. In the study by Gentile (2011), more boys than girls played video games and developed addiction; boys also played longer than girls. Similarly, in Rehbein's (2013) studies, male gender was found to be an important factor in the development of pathological gaming in children and adolescents.

Existing studies indicate that, for example, with regard to behaviour related to the Internet, interpersonal rather than interpersonal factors are stronger (Koo \& Kwon, 2014). Special roles are played by individuals' predispositions, including self-related variables (such as escape from one's self or identity), temperamental variables, control and regulation of emotions, exacerbation of negative emotions and negative coping strategies. Contrary to expectations, a much lesser role in the pathological development of internet use is played by factors associated with social relations, including family functionality, parental behaviour and the social skills of adolescents. The younger the age group, the greater the potency of risk factors (Koo \& Kwon, 2014). Gentile (2011) has identified the following early predictors of the development of pathological video gaming in children: early start of gaming, low empathy, and high impulsivity. These factors not only initiate gaming but also contribute to the development of pathological gaming and the consequent increase in depression, anxiety, social phobia and low academic performance. In the literature, there is a discussion about whether the risk factors of behavioural addiction in children and young people are culturally dependent. Indeed, the prevalence of addictive behaviour regarding video games across countries is similar, $0.5-8.5 \%$ of the gaming population is addicted to video games (Schmit, Chauchard, Chabrol, \& Sejourne, 2011; Gentile et al., 2011), while among adolescent gamers this percentage is $1.7-8 \%$ (Rehbein et al., 2015; Mentzoni et al., 2011). The effects of playing pro-social and violent games are also similar (Kirsh, 1998, 2003; Gentile et al., 2009). However, certain countries are different, for example, in terms of access to broadband Internet or the method of education, which may be associated with pathological gaming. These issues undoubtedly require further empirical verification.

Another risk factor for the development of behavioural addictions is parental behaviour (Griffiths, 2010), both related to behavioural modelling and the quality of parental involvement. For example, in a Canadian study of 938 students, a link was found between parental gambling and the low quality of parental responsibility and pathological gaming in children (Vachon, Vitaro, Wanner, \& Tremblay, 2004). The frequency of gambling in both parents was correlated with the frequency of gambling in their children; however, pathological gaming in adolescents was correlated only with the intensity of problem behaviours in fathers. Studies have also revealed a relationship between poor control and inadequate parental discipline and adolescent involvement in gambling activities and the subsequent development of addiction. In studies on Internet addiction in young people, a relationship was found between the quality of parenting and family functioning and pathological use of the Internet, although the relationships were weaker than expected (Koo \& Kwon, 2014).

\section{SUMMARY}

Behavioural addictions are slowly becoming a defining feature of our times. By applying the perspective of developmental psychopathology, we can better understand the specific issues associated with the complex system of conditioned behavioural dependencies in which biological, psychological and social factors are in constant interaction. Recognition of the differentiation of developmental pathways that lead to healthy or pathological pathways allows us to explain the complexity of the mechanisms responsible for initiating and sustaining addictive behaviours. It also enables the development of effective prevention and treatment programmes.

\section{REFERENCES}

American Psychiatric Association. (2000). Diagnostic and statistical manual of mental disorders ( $4^{\text {th }}$ ed., text rev.). Washington, DC: Author.

American Psychiatric Associations. (2013). Diagnostic and statistical manual of mental disorders ( $5^{\text {th }}$ ed.). Arlington, VA: American Psychiatric Publishing.

Bachman, J. G., Wadsworth, K. N., O'Malley, P. M., Johnston, L. D., \& Schulenberg, J. E. (1997). Smoking, drinking, and drug use in young adulthood: The impacts of new freedoms and new responsibilities. Erlbaum: Mahwah, NJ.

Blaszczynski, A., \& Nower, L. (2002). A pathways model of problem and pathological gambling. $A d-$ diction, 97, 487-499.

Blaszczynski, A., \& Nower, L. (2005). A pathway approach to treating youth gamblers. In J. L. Derevensky \& R. Gupta (eds.), Gambling Problem in Youth. Theoretical and Applied Perspective. New York, NY: Kluwer Academic/Plenum Publishers.

Chambers, R. A., \& Potenza, M. N. (2003). Neurodevelopment, impulsivity, and adolescent gambling. Journal of Gambling Study, 19, 53-84. 
Chassin, L., Sher, K., Hussong, A., \& Curran, P. (2013). The developmental psychopathology of alcohol use and alcohol disorders: Research achievements and future directions. Development and Psychopathology, 25, 1567-1584.

Chein, J., Albert, D., O’Brien, L., Uckert, K., \& Steinberg, L. (2011). Peers increase adolescent risk taking by enhancing activity in the brain's reward circuitry. Developmental Science, 14, 1-10.

Cicchetti, D. (1993). Developmental psychopathology: Reactions, reflections, projections. Developmental Review, 13, 471-502.

Cicchetti, D. (2013). An overview of developmental psychopathology. In P. Zelazo (ed.), The Oxford handbook of developmental psychology (pp. 455480). New York: Oxford University Press.

Cicchetti, D., \& Rogosch, F. A. (1996). Equifinality and multifinality in developmental psychopathology. Development and Psychopathology, 8, 597-600.

Cierpiałkowska, L. (2010). Modele genetyczne i koncepcje psychologiczne zaburzeń związanych z używaniem alkoholu [Genetic patterns and psychological concepts of alcohol use disorders]. In L. Cierpiałkowska \& M. Ziarko, Psychologia uzależnień - alkoholizm [Dependence psychology alcoholism] (pp. 113-186). Warsaw: WSiP.

Cierpiałkowska, L., \& Grzegorzewska, I. (2016). Dzieci alkoholików w perspektywie rozwojowej i klinicznej [Children of alcoholics in develpmetal and clinical perspective]. Poznan: Wydawnictwo UAM.

Compas, B. E., Hinden, B. R., \& Gerhardt, C. A. (1995). Adolescent development: pathways and processes of risk and resilience. Annual Review of Psychology, 46, 265-293.

Conrod, P. J., O'Leary-Barrett, M., Newton, N., Topper, L., Castellanos-Ryan, N., Mackie, C., \& Girard A. (2013). Effectiveness of a selective, personality-targeted prevention program for adolescent alcohol use and misuse: A cluster randomized controlled trial. JAMA Psychiatry, 70, 334-342.

Davies, T., \& Cranston, P. (2008). Youth Work and Social Networking: Final Research Report. Leicester: National Youth Agency.

Filip, M. (2013). Nowe uzależnienia XXI wieku [New addictions of the $21^{\text {st }}$ century]. Wszechświat, 114, 2592-2594.

Garmezy, N. (1985). Stress-resistant children: The search for protective factors. In A. Davids (ed.), Recent research in developmental psychopathology (pp. 213-233). Elmsford, NY: Pergamon Press.

Gearhardt, A. N., Corbin, W. R., \& Brownell, K. D. (2009). Preliminary validation of the Yale Food Addiction Scale. Appetite, 52, 430-436.

Gearhardt, A. N., Roberto, C. A., Seamans, M. J., Corbin, W. R., \& Brownell, K. D. (2013). Preliminary validation of the Yale Food Addiction Scale for children. Eating Behaviors, 14, 508-512.
Gentile, D. A., Choo, H., Liau, A., \& Khoo, A. (2011). Pathological video game use among youths: a two-year longitudinal study. Pediatrics, 127, 319-329.

Gentile, D. A, Anderson, C. A., Yukawa, S., Ihori, N., \& Saleem, M. (2009). The effects of prosocial video games on prosocial behaviors: international evidence from correlational, longitudinal, and experimental studies. Personality and Social Psychology Bulletin, 35, 752-763.

Goudriaan, A. E., Oosterlaan, J., De Beurs, E., \& Van Den Brink, W. (2008). The role of self-reported impulsivity and reward sensitivity versus neurocognitive measures of disinhibition and decision-making in the prediction of relapse in pathological gamblers. Psychological Medicine, 38, 41-50.

Grant, J., \& Kim, S. (2001). Demographic and clinical features of 131 adult pathological gamblers. Journal of Clinical Psychiatry, 62, 957-962.

Griffiths, M. D. (2003). Adolescent gambling: risk factors and implications for prevention, intervention, and treatment., Reducing adolescent risk: toward an integrated approach. In D. Romer (ed.), Reducing adolescent risk: toward an integrated approach (pp. 223-238). Thousand Oaks, Calif., London: Sage Publications.

Griffiths, M. D. (2010). The role of parents in the development of gambling behaviour in adolescents. Education and Health, 28, 51-54.

Grzegorzewska, I. (2013). Odporność psychiczna dzieci alkoholików [Resilience of children of alcoholics]. Warsaw: Wyd. Scholar.

Grzegorzewska, I., \& Cierpiałkowska, L. (2017). Uzależnienia behawioralne [Behavioral addiction]. Warsaw: PWN [Manuscript in preparation].

Hawkins, J. D., \& Fitzgibbon, J. J. (1993). Risk Factors and Risk Behaviors in Prevention of Adolescent Substance Abuse. Adolescent Medicine, 4, 249-262.

Israelashvili, M., Kim, T., \& Bukobza, G. (2012). Adolescents' over-use of the cyber world - Internet addiction or identity exploration? Journal of Adolescence, 35, 417-424.

Jacobs, D. (2000). Juvenile gambling in North America: An analysis of long term trends and future prospects. Journal of Gambling Studies, 26, 119-152.

Juczyński, Z. (2008). Dylematy i kontrowersje dotyczące uzależnień [Dilemmas and controversy concerning addiction]. In J. Brzeziński \& L. Ciepiałkowska (eds.), Zdrowie i choroba. Problemy teorii, diagnozy i praktyki [Health and disease. Problems of theory, diagnosis And practice] (pp. 190-212). Gdansk: Gdańskie Wydawnictwo Psychologiczne.

Kirsh, S. J. (1998). Seeing the world through Mortal Kombat-colored glasses: Social Video games and the development of a short-term hostile attribution bias. Childhood, 5, 177-184.

Kirsh, S. J. (2003). The effects of violent video games on adolescents The overlooked influence of de- 
velopment. Aggression and Violent Behavior, 8, 377-389.

Koo, H. J., \& Kwon, J. H. (2014). Risk and protective factors of Internet addiction: a meta-analysis of empirical studies in Korea. Yonsei Medical Journal, 55, 1691-1711.

Krueger, R. F., \& Markon, K. E. (2011). A dimensional-spectrum model of psychopathology: Progress and opportunities. Archives of General Psychiatry, $68,10-11$.

Krueger, R. F., Markon, K. E., Patrick, C. J., Benning, S. D., \& Kramer, M. D. (2007). Linking antisocial behavior, substance use, and personality: An integrative quantitative model of the adult externalizing spectrum. Journal of Abnormal Psychology, 116, 645-666.

Ladouceur, R., Dube, D., \& Bujold, A. (1994). Gambling Among Primary School Students. Journal of Gambling Studies, 10, 363-370.

Maclaren, V. V., Fugelsang, J. A., Harrigan, K. A., \& Dixon, M. J. (2011). The personality of pathological gamblers: A meta-analysis. Clinical Psychology Review, 31, 1057-1067.

Mentzoni, R. A., Brunborg, G. S., Molde, H., Myrseth, H., Skouverøe, K. J, Hetland, J., \& Pallesen, A. (2011). Problematic video game use: estimated prevalence and associations with mental and physical health. Cyberpsychology, Behavior, and Social Networking, 14, 591-596.

Moffitt, T. E., Arseneault, L., Belsky, D., Dickson, N., Hancox, R. J., Harrington, H., ...Caspi, A. (2011). A gradient of childhood self-control predicts health, wealth, and public safety. Proceedings of the National Academy of Sciences, 108, 2693-2698.

Niemz, K., Griffiths, M., \& Banyard, P. (2005). Prevalence of pathological Internet use among university students and correlations with self-esteem, the General Health Questionnaire (GHQ), and disinhibition. CyberPsychology \& Behavior, 8, 562-570.

Ofrat, S., \& Krueger, R. F. (2012). How research on the meta-structure of psychopathology aids in understanding biological correlates of mood and anxiety disorders. Biology of Mood \& Anxiety Disorders, 2, 13.

Paus, T. (2005). Mapping brain maturation and cognitive development during adolescence. Trends in Cognitive Sciences, 9, 60-68.

Petry, N. (2015). Behavioral addictions. Oxford: Oxford Press.

Poprawa, R. (2015). Skazani na problemy. W poszukiwaniu osobowościowych uwarunkowań angażowania się mężczyzn w piciu alkoholu [Convicted od problems. In search of personality conditioning of drinking problem in men]. Warsaw: Wydawnictwo SCHOLAR.

Rehbein, F., \& Baier D. (2013). Family-, Media-, and School-Related Risk Factors of Video Game Addiction: A 5-Year Longitudinal Study. Journal of Media Psychology, 25, 118-128.
Rehbein, F., Kliem, S., Baier, D., Mößle, T., \& Petry N. M. (2015). Prevalence of internet gaming disorder in German adolescents: diagnostic contribution of the nine DSM-5 criteria in a state-wide representative sample. Society for the Study of Addiction. doi: 10.1111/add.12849

Rosenberg, K. P., \& Feder, L. C. (2014). Behavioral addictions. Criteria, Evidence, Treatment. Elsevier.

Rutter, M., Dunn, J., Plomin, R., Simonoff, E., Pickles, A., Maughan, B., ...Eaves, L. (1997). Integrating nature and nurture: Implications of person-environment correlations and interactions for developmental psychopathology. Development and Psychopathology, 9, 335-364.

Rutter, M., \& Rutter, M. (1992). Developing minds: Challenges and continuity across the life span. New York: Basic Books.

Ryan, R. M., Rigby, C. S., \& Przybylski, A. (2006). The motivational pull of video games: A self-determination theory approach. Motivation and Emotion, 30, 347-364.

Sameroff, A. J. (2000). Developmental systems and psychopathology. Development and Psychopathology, 12, 297-312.

Schmit, S., Chauchard, E., Chabrol, H., \& Sejourne, N. (2011). Evaluation of the characteristics of addiction to online video games among adolescents and young adults. Encephale, 37, 217-223 [Article in French].

Steinberg, L. (2008).A social neuroscience perspective on adolescent risk-taking. Developmental Review, 28, 78-106.

Streit, F, \& Oliver, H. G., Jr. (1972). The Child's Perception of His Family and Its Relationship to Drug Use, Drug Forum 1, 283-289.

Tapert, S. F., Caldwell, L., \& Burke, C. (2005). Alcohol and the adolescent brain: Human studies. Alcohol Research \& Health, 28, 205-212.

Trempała, J., \& Cieciuch, J. (2016). The analysis of change in behavior and development: on some errors and possibilities to correct them. Current Issues in Personality Psychology, 4, 65-74.

Vachon, J., Vitaro, F., Wanner, B., \& Tremblay, R. E. (2004). Adolescent gambling: Relationships with parent gambling and parenting practices. Psychology of Addictive Behaviors, 18, 398-401.

Wood, R. T., \& Griffiths, M. D. (1998). The acquisition, development, and maintenance of lottery and scratchcard gambling in adolescence. Journal of Adolescence, 21, 265-273.

World Health Organisation. (1992). International Statistical Classification of Diseases and Related Health Problems, $10^{\text {th }}$ Revision (ICD-10).

Wölfling, K., \& Müller, K. W. (2009). Computerspielsucht. In D. Batthyány \& A. Pritz (eds.), Rausch ohne Drogen. Substanzgebundene Süchte [Intoxication without drugs. Substance-bound addictions] (pp. 291-308). New York: Springer. 